\title{
Long-Term Treatment with an Herbal Formula MCC Reduces the Weight Gain in High Fat Diet-Induced Obese Mice
}

\author{
Pou Kuan Leong ${ }^{1}$, Hoi Yan Leung ${ }^{1}$, Hoi Shan Wong ${ }^{1}$, Jihang Chen ${ }^{1}$, Chung Wah Ma ${ }^{2}$, \\ Yiting Yang ${ }^{2}$, Kam Ming Ko ${ }^{{ }^{*}}$ \\ ${ }^{1}$ Division of Life Science, Hong Kong University of Science and Technology, Hong Kong, China \\ ${ }^{2}$ Infinitus (China) Company Ltd., Guangzhou, China \\ Email: "bcrko@ust.hk
}

Received June 5, 2013; revised July 6, 2013; accepted July 18, 2013

Copyright (C) 2013 Pou Kuan Leong et al. This is an open access article distributed under the Creative Commons Attribution License, which permits unrestricted use, distribution, and reproduction in any medium, provided the original work is properly cited.

\begin{abstract}
Obesity is a risk factor for metabolic disorders, with its prevalence being increased in the world over the past several decades. Therapeutical interventions for obesity are thus urgently needed. In the present study, we investigated the effect of long-term treatment $(0.51$ and $5.1 \mathrm{~g} / \mathrm{kg} / \mathrm{day}, 5$ days per week for a total of 40 doses $)$ with an herbal formula MCC [which comprises the fruit of Momordica charantia (MC), the pericarpium of Citri reticulata and L-carnitine] in normal diet (ND) and high fat diet (HFD)-fed female ICR mice. Body weight change was monitored during the course of the experiment. Fat pad indices, plasma glucose and lipid contents, as well as metabolic enzyme activities and mitochondrial coupling efficiency in skeletal muscle were measured at 24 hours after the last dosing. Results showed that HFD increased the body weight, fat pad indices, plasma glucose and lipid contents as well as $\beta$-hydroxyacyl-Co A dehydrogenase $(\beta$-HAD) and carnitine palmitoyl CoA transferase (CPT) activities in skeletal muscle. However, the phosphofructokinase (PFK) activity was decreased in skeletal muscle. MCC treatment reduced the HFD-induced increases in body weight, fat pad indices and plasma lipid contents. MCC treatment only partially reversed the HFD-induced changes in $\beta$-HAD and CPT activities, but did not restore the HFD-induced decrease in PFK activity. MCC did not alter the plasma glucose level and mitochondrial coupling efficiency in skeletal muscle of ND and HFD-fed mice. Since MCC formula did not increase activities of energy metabolic enzymes or induce mitochondrial uncoupling, the weight loss effect of MCC is likely related to the reduction of intestinal lipid absorption in HFD-fed mice.
\end{abstract}

Keywords: Obesity; Weight Control; Momordica Charantia; Citri Reticulata; L-Carnitine

\section{Introduction}

Obesity has become an overt worldwide epidemic. In $2005,1.1$ billion adults as well as $10 \%$ of children were regarded as overweight or obese over the world [1]. In $2007,16.4 \%$ and $31.6 \%$ children were classified as obese and overweight, respectively, in the United States [2]. Recent evidence suggests that adolescent obesity correlates well with an elevated risk of severe obesity [i.e. body mass index $(\mathrm{BMI})>40$ ] in adulthood [3]. More importantly, obesity is associated with a number of disorders, including cardiovascular diseases, cerebrovascular diseases, cancers, type 2 diabetes mellitus, and metabolic syndrome (see reviewed in [4]). Recent studies have shown that an excessive visceral (intra-abdominal)

"Corresponding author. adipose tissue, but not subcutaneous abdominal fat, is associated with metabolic abnormalities (or metabolic syndrome) in overweight/obese patients [5], with a resultant increased risk of atherosclerotic cardiovascular diseases [6]. Fatty acid metabolites arising from an excessive cellular lipid accumulation in skeletal muscle cells may induce insulin resistance, thereby leading to dyslipidemia and hyperglycemia [7]. Obesity thus poses a severe economic burden on healthcare systems in many countries, and effective anti-obesity therapies are therefore urgently needed.

To mobilize the lipid reservoir in the body, skeletal muscle tissue plays a crucial role, wherein $90 \%$ of the energy expenditure of skeletal muscle is obtained from fatty acid oxidation, particularly in resting state [8]. Given that muscle is the major organ utilizing fatty acids 
as a primary fuel, physical exercise is a commonly used intervention for the treatment of obesity and metabolic syndrome. In support of this view, the physical exercise-induced activation of AMP kinase was found to stimulate glucose uptake in insulin signaling-impaired skeletal muscle [9]. However, compliance with conventional lifestyle intervention, which involves regular physical exercises and low calorie diet, is low [10]. An alternative approach to treating obesity should be therapeutic interventions, which involve digestive enzyme inhibition or appetite suppression. In this regard, orlistat (a pancreatic lipase inhibitor) and amphetamine (a stimulator of central noradrenaline release) are currently available drugs in the market. Notwithstanding their antiobesity efficacy, some patients prescribed with orlistat/ amphetamine showed adverse side effects, which include steatorrhoea and liver injury, as were the cases for orlistat, and addiction and hypertension, as were the cases for amphetamine [11].

In an attempt to develop an effective, palatable and safe intervention for obesity, herbal medicine, which has a long history of use in different cultures for weight reduction, may offer a promising prospect. Recently, a growing body of evidence has been accumulated showing the effectiveness of herbal medicine in controlling obesity. As such, the fruit of Momordica charantia (MC, also called bitter melon) was found to attenuate the high calorie diet-induced hypertrophy of adipose tissue in rodents $[12,13]$, presumably through the down-regulation of lipogenic gene expression [12] as well as the induction of lipid oxidative enzymes and uncoupling protein expression [13]. The pericarpium of Citri reticulata (CR), which contains a range of flavonoids, such as tangeretin, hesperidin, citromitin, nobiletin, neohesperidin and dlimonene, is regarded as a potential herbal medicine for weight control. Hesperidin, the principal flavonoid found in CR, and nobiletin were found to suppress the mRNA level of stearoyl-Co A desaturease, a key lipogenic enzyme [14]. Hesperidin can also slightly suppress the growth of cultured pre-adipocytes [15]. On the other hand, L-carnitine, which carries fatty acid from the cytosol to mitochondrial matrix, was found to cause an effective stimulation of metabolic flux through pyruvate dehydrogenase complex and mitochondrial oxidative processes during high intensity exercise [16].

In the present study, we sought to evaluate the effect of MCC, an herbal formula comprising MC, CR and L-carnitine, on high fat diet-induced obesity in female ICR mice. The body weight, visceral (gonadal and mesenteric) and subcutaneous fat pads, plasma glucose level, plasma lipid contents [triglyceride (TG), low density lipoprotein cholesterol (LDL-C) and high density lipoprotein cholesterol (HDL-C) were measured. To examine the metabolic status of skeletal muscle, activities of myocellular phosphofructokinase (PFK), $\beta$-hydroxyacylCo A dehydrogenase ( $\beta$-HAD), carnitine palmitoyl CoA transferase (CPT) and citrate synthase (CS) were also measured. To assess the mitochondrial functional status, state 3 and state 4 respiratory rates were measured using mitochondria isolated from skeletal muscle of mice. Coupling efficiency was estimated by computing the ratio of state 3 to state 4 mitochondrial respiratory rates.

\section{Materials and Methods}

\subsection{Chemicals}

PicoLab $^{\circledR}$ Rodent diet 20 (normal diet) was purchased from LabDiet ${ }^{\circledR}$ (City, State, USA). The "Original" High Fat Diet (Diet-induced Obesity Formula D12492, 60\% energy from fat) was purchased from Research Diets, Inc. (New Brunswick, NJ, USA). TG and cholesterol assay kits were purchased from Wako Pure Chemical Industries, Ltd. (Okasa, Japan). HDL-C test kit was purchased from Wako Diagnostics (Richmond, VA, USA). Glucose assay reagent was obtained from Sigma Chemical Co. (St. Louis, MO, USA). All other chemicals were of analytical grade.

\subsection{Herbal Preparation}

MCC is mainly comprised of water extracts of MC (42\%, $\mathrm{w} / \mathrm{w})$ and CR (14\%) as well as L-carnitine (8\%). The commercial preparation was manufactured and supplied by Infinitus (China) Company Ltd., Guangzhou, China.

\subsection{Animal Care}

Adult female ICR mice (8 - 10 weeks old, 20 - $25 \mathrm{~g}$ ) were maintained under a 12-hour dark/light cycle at about $22^{\circ} \mathrm{C}$, and allowed food and water ad libitum in the Animal and Plant Care Facility at the Hong Kong University of Science and Technology (HKUST). All experimental protocols were approved by the University Committee on Research Practice at HKUST.

\subsection{Animal Treatment}

ICR mice were randomly assigned to 6 groups, with 10 15 mice in each: 1) Normal diet (ND, 13\% energy from fat) control, 2) ND + low dose $\mathrm{MCC}(0.51 \mathrm{~g} / \mathrm{kg}), 3) \mathrm{ND}$ + high dose MCC (5.1 g/kg), 4) High fat diet (HFD, 60\% energy from fat) control, 5) HFD + low dose MCC (0.51 $\mathrm{g} / \mathrm{kg}$ ) and 6) HFD + high dose MCC (5.1 g/kg). The low dose was estimated from the recommended oral dose for human usage after adjusting for the interspecies difference in drug distribution in the body [17]. In the drug treatment groups, mice were intragastrically administered with MCC, 5 days per week for 8 weeks (i.e. 40 doses). Control mice received water (vehicle) only. Twenty-four 
hours after the last dosing, blood samples were drawn from overnight fasted, phenobarbital-anesthetized mice by cardiac excision using syringes rinsed with $0.5 \%$ heparin in saline (w/v), and the mice were then sacrificed by cervical dislocation. Samples of gastrocnemius muscle and fat pads (gonadal, retroperitoneal, and mesenteric fat) were excised, and they were subjected to further analysis.

\subsection{Preparation of Samples}

Plasma samples were obtained by centrifuging whole blood samples at $1500 \times g$ for 10 minutes at $4^{\circ} \mathrm{C}$. Plasma samples were then subjected to biochemical analysis.

Minced gastrocnemius muscle tissues were mixed with $10 \mathrm{~mL}$ collagenase solution $[0.075 \%(\mathrm{w} / \mathrm{v})$ in buffer], and the mixtures were incubated at $4{ }^{\circ} \mathrm{C}$ for $20 \mathrm{~min}$. The digested tissue mixtures were centrifuged at $600 \times g$ at $4^{\circ} \mathrm{C}$ for $20 \mathrm{~min}$. After removing the supernatant, the digested tissues were mixed with $20 \mathrm{~mL}$ of ice-cold homogenizing buffer (100 mM KCl, $50 \mathrm{mM}$ MOPS, 10 mM EGTA, pH 7.2) and subjected to homogenization with a Teflon-glass homogenizer at 4,000 rpm for 25 - 30 complete strokes. Then the homogenates were centrifuged at $600 \times \mathrm{g}$ for $10 \mathrm{~min}$ at $4^{\circ} \mathrm{C}$. The resultant supernatant was nucleus-free fraction. For measurements of $\beta$-HAD, CS and CPT activities, nucleus-free fraction was diluted with $0.2 \%$ Triton $\mathrm{X}-100\left(\mathrm{w} / \mathrm{v}\right.$ in $\mathrm{K}_{2} \mathrm{HPO}_{4}$ buffer) $[18,19]$.

Mitochondrial pellets were prepared from muscle homogenates by centrifugation at $9200 \times g$ at $4^{\circ} \mathrm{C}$ for 30 $\mathrm{min}$. The mitochondrial pellets were then resuspended in a buffer containing $250 \mathrm{mM}$ sucrose, $50 \mathrm{mM}$ Tris, $\mathrm{pH} 7.5$ [20,21].

\subsection{Measurement of Body Weight and Fat Pad Weight}

Body weight of mice was measured once a week during the 8-week course of experiment. Gonadal, mesenteric and subcutaneous fat pads were weighed. The ratio of a particular fat pad weight to body weight was estimated and expressed as fat pad index [22,23].

\subsection{Biochemical Analysis}

Plasma glucose levels were measured using an assay kit basing on coupled hexokinase-catalyzed and glucose6-phosphate dehydrogenase-catalyzed reactions, with a resultant NAD reduction. Absorbance changes at $340 \mathrm{~nm}$ were monitored spectrophotometrically by Victor ${ }^{3}$ Multilabel Counter (Perkin Elmer, Turku, Finland).

Plasma levels of TG, HDL-C and TC levels were measured using assay kits. In brief, TG levels were measured spectrophotometrically by an enzymatic method using the quantitative production of N-ethyl-N-(2-hy- droxy-3-sulfopropyl)-3,5-dimethoxyaniline sodium salt (DAOS, a blue pigment) via coupled reactions. HDL-C was measured spectrophotometrically by the method of phosphotungstate-magnesium salt precipitation. TC levels were measured by an enzymatic colorimetric method basing on the quantitative production of DAOS from coupled reactions. In the above assays, their end products were measured by monitoring the changes in absorbance at $600 \mathrm{~nm}$. LDL-C level was estimated by Friedewald's formula: $\mathrm{LDL}=\mathrm{TC}-(\mathrm{HDL}-\mathrm{C}+\mathrm{TG} / 5)$ [24].

PFK activity was measured with a reaction cocktail containing $50 \mathrm{mM}$ Tris- $\mathrm{HCl}(\mathrm{pH} 7.4), 5 \mathrm{mM} \mathrm{MgCl} 2,5$ $\mathrm{mM}\left(\mathrm{NH}_{4}\right)_{2} \mathrm{SO}_{4}, 1 \mathrm{mM}$ fructose-6-phosphate, $1 \mathrm{mM}$ ATP, $0.5 \mathrm{mM}$ NADH, $2 \mathrm{mU} / \mathrm{mL}$ aldolase, $2 \mathrm{mU} / \mathrm{mL}$ triose phosphate isomerase, $2 \mathrm{mU} / \mathrm{mL} \alpha$-glycerophosphate dehydrogenase and $50 \mu \mathrm{g} / \mathrm{mL}$ of protein (muscle nucleusfree fraction) in a final volume of $200 \mu \mathrm{L}$. The reaction was initiated by the addition of nucleus-free fraction. NADH oxidation was measured by monitoring the changes in absorbance at $340 \mathrm{~nm}$ [19].

$\beta$-HAD activity was measured in $100 \mathrm{mM}$ potassium phosphate buffer with $2 \mathrm{mM}$ EDTA, pH 7.3. The reaction was started by the addition of $100 \mu \mathrm{M}$ acetoacetyl-CoA and $100 \mu \mathrm{M} \beta$-NADH, and absorbance changes at $340 \mathrm{~nm}$ were monitored for $2 \mathrm{~min}$ at $30^{\circ} \mathrm{C} \mathrm{[25].}$

A reaction cocktail for measuring $\mathrm{CS}$ activity was prepared by mixing $0.1 \mathrm{M}$ Tris buffer $(\mathrm{pH} 8.0), 0.058$ $\mathrm{mM}$ acetyl CoA, and $0.1 \mathrm{mM}$ dithionitrobenezene (DTNB). The reaction was initiated by the addition of oxaloacetate (final concentration: $0.5 \mathrm{mM}$ ). Absorbance at $412 \mathrm{~nm}$ was recorded every $30 \mathrm{~s}$ for $3 \mathrm{~min}$ at $30^{\circ} \mathrm{C}$. The CS activity is also considered as an indirect measure of mitochondrial content in muscle tissue [26,27].

To measure the CPT activity, the reaction was initiated by adding L-carnitine (final concentration $6 \mu \mathrm{M}$ ) to the reaction mixture (16 $\mathrm{mM}$ Tris, $2.5 \mathrm{mM}$ EDTA, $2 \mathrm{mM}$ DTNB and $50 \mu \mathrm{M}$ palmitoyl-CoA, $\mathrm{pH}$ 8.0). The absorbance at $412 \mathrm{~nm}$ was monitored for $180 \mathrm{~s}$ at $30^{\circ} \mathrm{C}$. The molar extinction coefficient of $13,600(\mathrm{~mol} / \mathrm{L})^{-1} \mathrm{~cm}^{-1}$ for 5'-thio-2-nitrobenzoate (end-product) was used for the estimation of enzyme activity. One unit of CPT activity is defined as the amount of enzyme catalyzing the release of $1 \mathrm{nmol} \mathrm{CoASH}$ per min [14,28-30].

\subsection{Measurement of Mitochondrial Respiration}

Mitochondrial respiratory was measured polarographically by a Clark-type oxygen electrode (Hansatech Instruments Ltd., Norfolk, UK) at $30^{\circ} \mathrm{C}$. Mitochondrial fraction $(\sim 0.5 \mathrm{mg}$ protein $/ \mathrm{mL})$ was incubated in a buffer containing $30 \mathrm{mM} \mathrm{KCl}, 6 \mathrm{mM} \mathrm{MgCl}, 75 \mathrm{mM}$ sucrose, 1

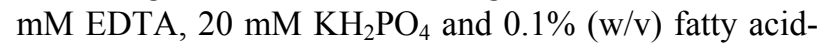
free BSA, pH 7.0. Substrate solution containing $10 \mathrm{mM}$ glutamate and $2.5 \mathrm{mM}$ malate was added, and after a 
stable state 2 respiration had been established, state 3 respiration (coupling) was initiated by the addition of ADP (final concentration $0.6 \mathrm{mM}$ ). When all of the added ADP was used up for ATP generation, oligomycin (ATP synthase inhibitor) was added to induce the state 4 respiration (uncoupling). The respiratory control ratio (RCR) was estimated by calculating the ratio of state 3 to state 4 respirations [21,31,32].

\subsection{Statistical Analysis}

Data were analyzed by one-way Analysis of Variance (ANOVA). Post-hoc multiple comparisons were performed using Least Significant Difference (LSD). P values $<0.05$ were regarded as statistically significant.

\section{Results}

\subsection{Effect of MCC on Body Weight in High Fat Diet-Induced Obese Mice}

The body weight of ND-fed mice was increased by $9 \%$ during the course of 8 -week experiment. MCC treatment at the high dose (i.e., $5.1 \mathrm{~g} / \mathrm{kg} /$ day) slightly but not significantly suppressed the body weight increase in ND-fed mice. HFD accelerated the body weight increase during the course of experiment, with the extent of stimulation being $219 \%$, when compared with that of the ND-fed mice (Figure 1). MCC treatment suppressed the body weight increase in HFD-fed mice, with the degree of inhibition being $46 \%$ and $68 \%$ at doses of 0.51 and $5.1 \mathrm{~g} / \mathrm{kg} /$ day, respectively (Figure 1).

\subsection{Effects of MCC on Fat Pad Indices in High Fat Diet-Induced Obese Mice}

The slight reduction in body weight increase afforded by MCC treatment $(5.1 \mathrm{~g} / \mathrm{kg} /$ day) in ND-fed mice was associated with the suppression of total fat pad index, with the extent of suppression being 66\% (Figure 2). The HFD-induced body weight increase was associated with the increase in total fat pad index, with the extent of elevation being $141 \%$, when compared with ND-fed control. Consistent with this, HFD also increased the indices of gonadal fat pad, mesenteric fat pad and subcutaneous fat pad, with the degree of stimulation being $170 \%, 125 \%$ and $57 \%$, respectively. MCC treatment dose-dependently suppressed the HFD-induced increase in total fat pad index, with the extent of suppression being $49 \%$ and $72 \%$. The suppression of total fat pad index increase afforded by MCC treatment was accompanied by decreases in indices of gonadal fat pad, mesenteric fat pad and subcutaneous fat pad, with the degree of reduction being 53\%, $33 \%$ and $72 \%$, respectively, at low dose and $73.65 \%$ and $96 \%$ at high dose.

\subsection{Effect of MCC on the Plasma Glucose Level and Lipid Contents}

Treatment with MCC did not alter the plasma glucose level and lipid contents in ND-fed mice, except a reduction of plasma TG $(25 \%)$ at the dose of $5.1 \mathrm{~g} / \mathrm{kg} / \mathrm{day}$. HFD feeding increased plasma glucose (30\%), TG (41\%), HDL-C (58\%) and LDL-C (124\%) levels as well as plasma LDL/HDL ratio (54\%) (Figure 3). MCC treatment also did not alter plasma glucose level in HFD-fed mice, but dose-dependently reversed the HFD-induced increase in plasma TG level (54\% and 113\%). MCC treatment $(0.51$ and $5.1 \mathrm{~g} / \mathrm{kg} /$ day $)$ reversed the HFDinduced increase in plasma HDL-C (47\% and 27\%, respectively) and LDL-C (70\% and 65\%) levels. However, treatment with MCC did not affect the plasma LDL/HDL ratio in HFD-fed mice.

\subsection{Effect of MCC on the Energy Metabolism Status of Skeletal Muscle}

To evaluate the effect of MCC on the energy metabo-

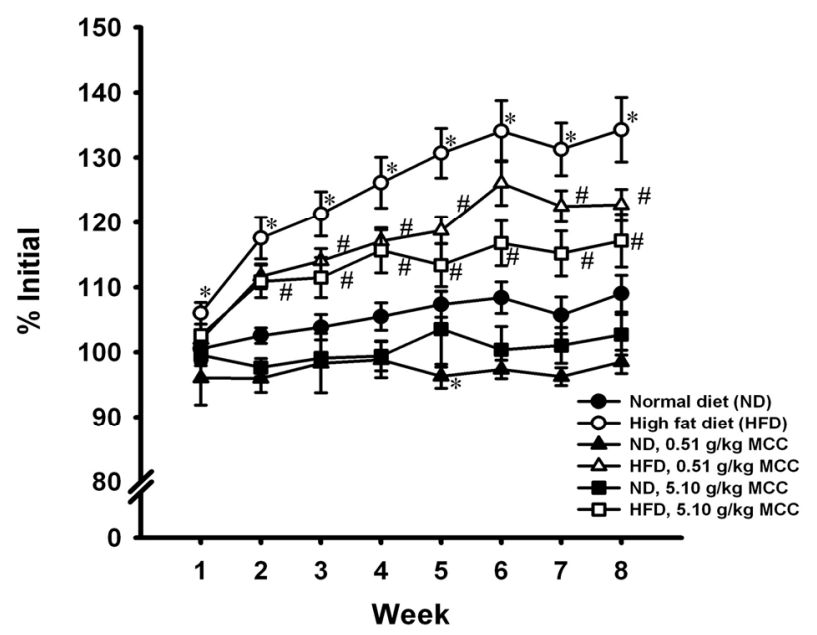

Figure 1. Effect of MCC treatment on the body weight in normal diet (ND) and high fat diet (HFD)-fed mice. Mice were allowed food [ND (13\% energy from fat) or HFD (60\% energy from fat)] and water ad libitum, during the course of 8-week experiment. In the drug treatment groups, mice were intragastrically administered with MCC (0.5 and $5.1 \mathrm{~g} / \mathrm{kg} / \mathrm{day}) 5$ days per week for 8 weeks (i.e. 40 doses), while control mice received water (vehicle) only. Body weights of mice were monitored by measuring the body weight of mice every week during the 8-week period. Data were expressed as \% initial, by normalizing with initial body weight (i.e. time $=$ week 0 ) of the respective mouse. Value given are means \pm SEM, with $n=10-15$. The initial body weight of each group were given as follows: 1) ND control = $29.6 \pm 1.0 \mathrm{~g} ; 2) \mathrm{ND}+0.51 \mathrm{~g} / \mathrm{kg}$ MCC $=33.3 \pm 1.5 \mathrm{~g} ; 3) \mathrm{ND}+$ $5.1 \mathrm{~g} / \mathrm{kg}$ MCC = $31.7 \pm 0.3 \mathrm{~g} ; 4)$ HFD control = $27.8 \pm 1.1 \mathrm{~g}$; 5) $\mathrm{HFD}+0.51 \mathrm{~g} / \mathrm{kg} \mathrm{MCC}=28.3 \pm 0.7 \mathrm{~g}$; and 6) HFD + 5.1 $\mathrm{g} / \mathrm{kg}$ MCC $=28.2 \pm 0.6 \mathrm{~g}$. ${ }^{*}$ Significantly different from timematched ND-fed control; " significantly different from timematched HFD-fed control. 

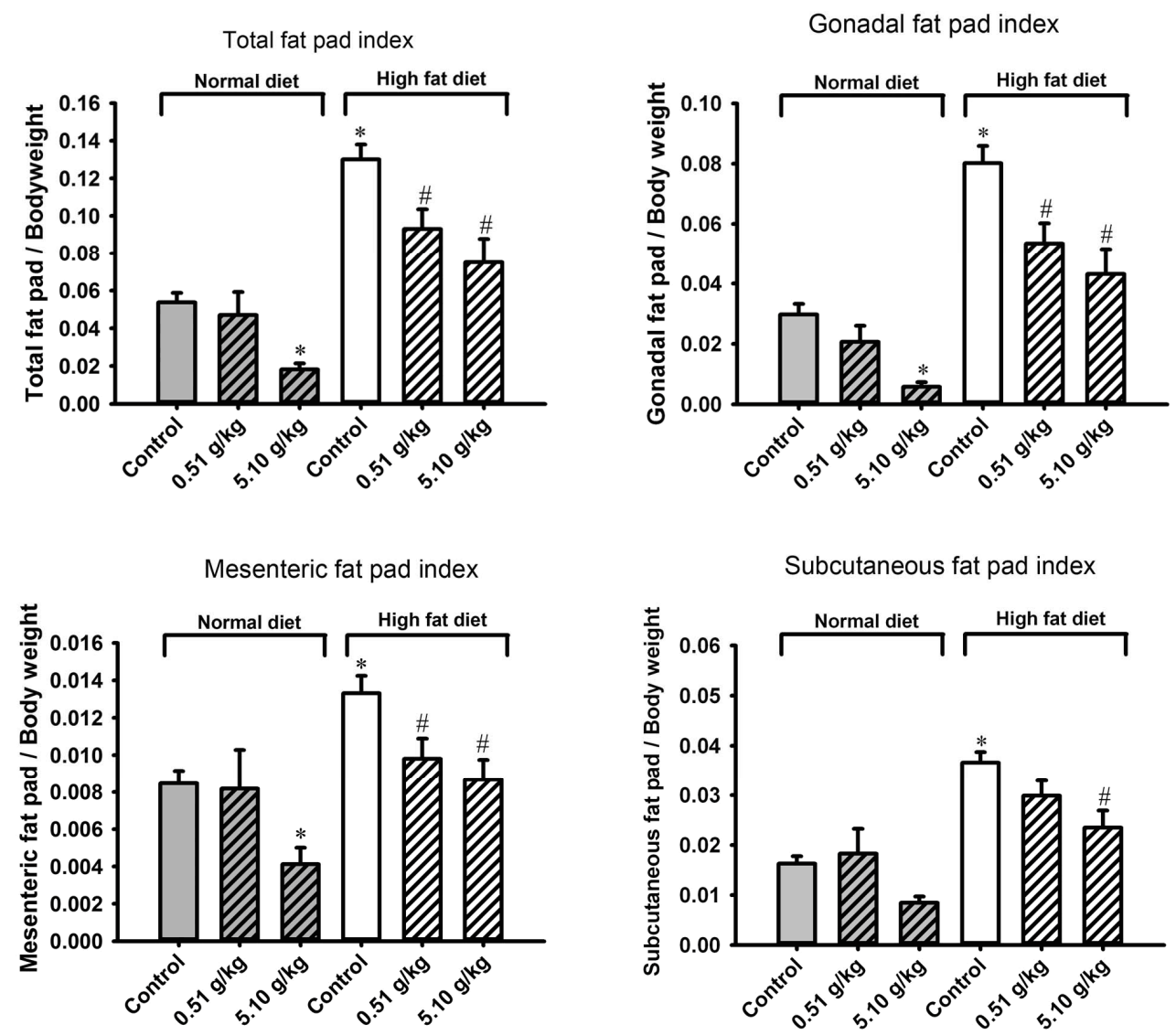

Figure 2. Effects of MCC treatment on the weight of various fat pads in normal diet (ND) and high fat diet (HFD)-fed mice. After the 8-week experiment, mice were sacrificed at $24 \mathrm{~h}$ after the last dosing of MCC. Gonadal, mesenteric and subcutaneous fat pads were excised and weighed. Total fat pad was the sum of gonadal, mesenteric and subcutaneous fat pads. Data were expressed as fat pad indices, by normalizing the fat pad weight with the body weight of the mouse. Values given are means \pm SEM, with $\mathbf{n}=10$ - 15. "Significantly different from ND control; ${ }^{*}$ significantly different from HFD control.

Lism status of skeletal muscle, activities of PFK (the rate-limiting enzyme of glycolysis), $\beta$-HAD as well as CPT (two essential enzymes of fatty acid $\beta$-oxidation) and CS (an indirect measure of mitochondrial content in muscle tissue) were measured. Treatment with MCC $(0.51$ and $5.1 \mathrm{~g} / \mathrm{kg} /$ day) suppressed the activities of $\beta$ HAD ( $13 \%$ and $15 \%$, respectively) and CPT (22\% and $14 \%$ ), but did not change the activities of PFK and CS in normal-diet fed mice. HFD feeding caused a decrease in PFK activity (19\%) but increases in $\beta$-HAD (14.6\%) and CPT $(27.5 \%)$ activities. Treatment with MCC did not change PFK and CS activities in HFD-fed mice. While MCC treatment reversed the HFD-induced increases in activity of CPT (by $44 \%$ and $110 \%$ ) in a dose-dependent manner, MCC treatment $(5.1 \mathrm{~g} / \mathrm{kg} /$ day $)$ suppressed the activity of $\beta$-HAD (96\%) in HFD-fed mice (Figure 4).

\subsection{Effect of MCC on the Mitochondrial Functional Status of Skeletal Muscle}

Coupling efficiency was indirectly assessed by estimat- ing the ratio of state 3 to state 4 mitochondrial respiratory rates. HFD feeding did not affect coupling efficiency (data not shown). MCC treatment did not produce any detectable changes in the coupling efficiency in both ND and HFD-fed mice (data not shown).

\section{Discussion}

In the present study, the HFD-induced body weight increase was associated with increases in subcutaneous and visceral fat pad indices, indicative of adipocyte hypertrophy in HFD-fed mice. In addition, HFD feeding increased plasma glucose and lipid contents, as well as decreased PFK activity in skeletal muscle of mice. In contrast, $\beta$-HAD and CPT activities were increased in skeletal muscle of HFD mice. As an excessive accumulation of visceral adipose tissue, but not subcutaneous abdominal fat, has been found to be associated with metabolic abnormalities in overweight/obese patients [5], the investigation of the inter-relationship between visceral adiposity and metabolic abnormalities has been an area 
Glucose

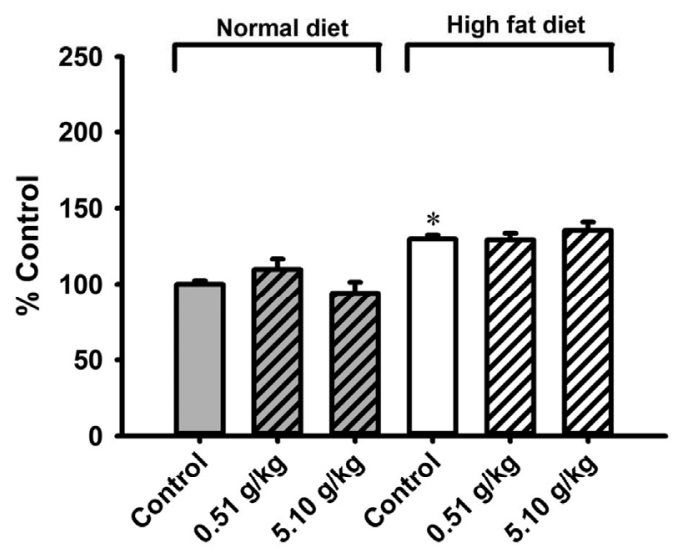

LDL-C

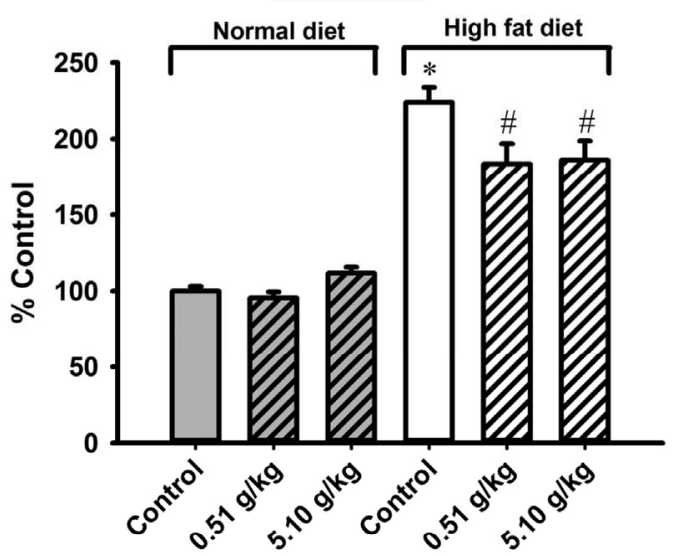

Ratio if LDL-C to HDL C

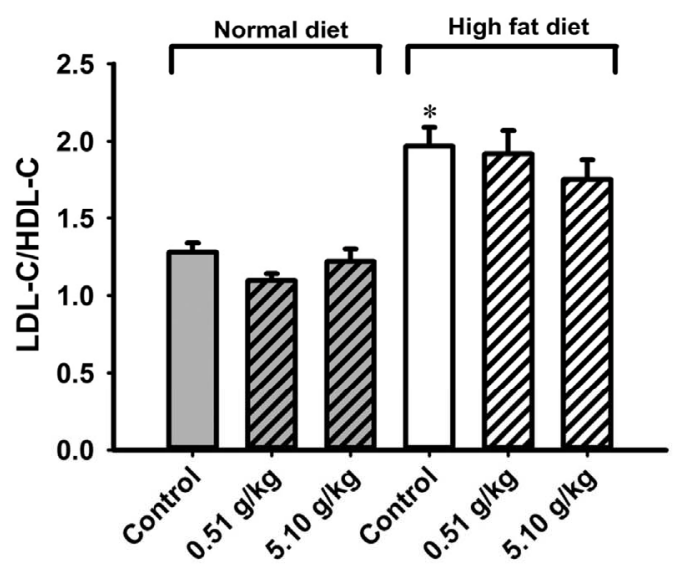

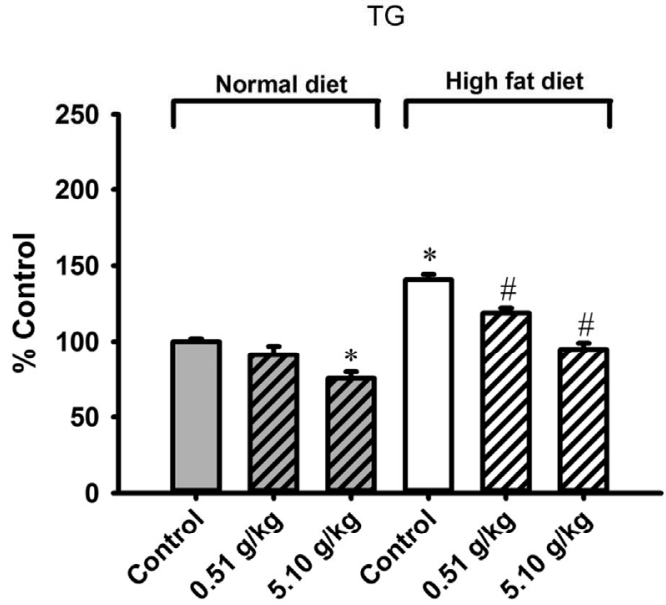

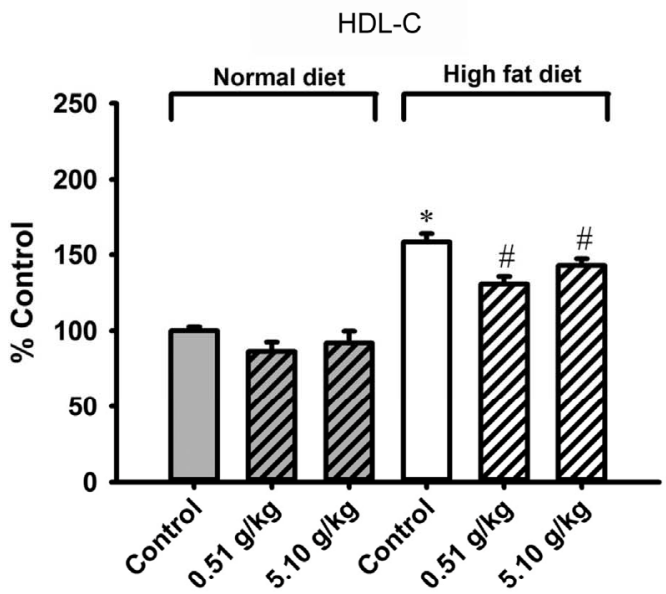

Figure 3. Effect of MCC treatment on the plasma glucose level and lipid contents in normal diet (ND) and high fat diet (HFD)-fed mice. Mice were sacrificed at $24 \mathrm{~h}$ after the last dosing of MCC as described in Figure 2. Plasma glucose level (ND control = 94.9 $\pm 3.6 \mathrm{mg} / \mathrm{dL}$ ), plasma triglyceride (TG) level (ND control = 58.8 $\pm 2.1 \mathrm{mg} / \mathrm{dL}$ ), low density lipoprotein cholesterol (LDL-C) level (ND control = $56.9 \pm 2.2 \mathrm{mg} / \mathrm{dL}$ ), high density lipoprotein cholesterol (HDL-C) level (ND control = $46.4 \pm$ $2.7 \mathrm{mg} / \mathrm{dL}$ ) and ratio of LDL-C to HDL-C (ND control = $1.28 \pm 0.06)$ were measured, as described in Materials and methods. Data were expressed as \% control, by normalizing with ND control. Value given are means \pm SEM, with $n=10$ - 15 . ${ }^{*}$ Significantly different from ND control; ${ }^{\#}$ significantly different from HFD control. 

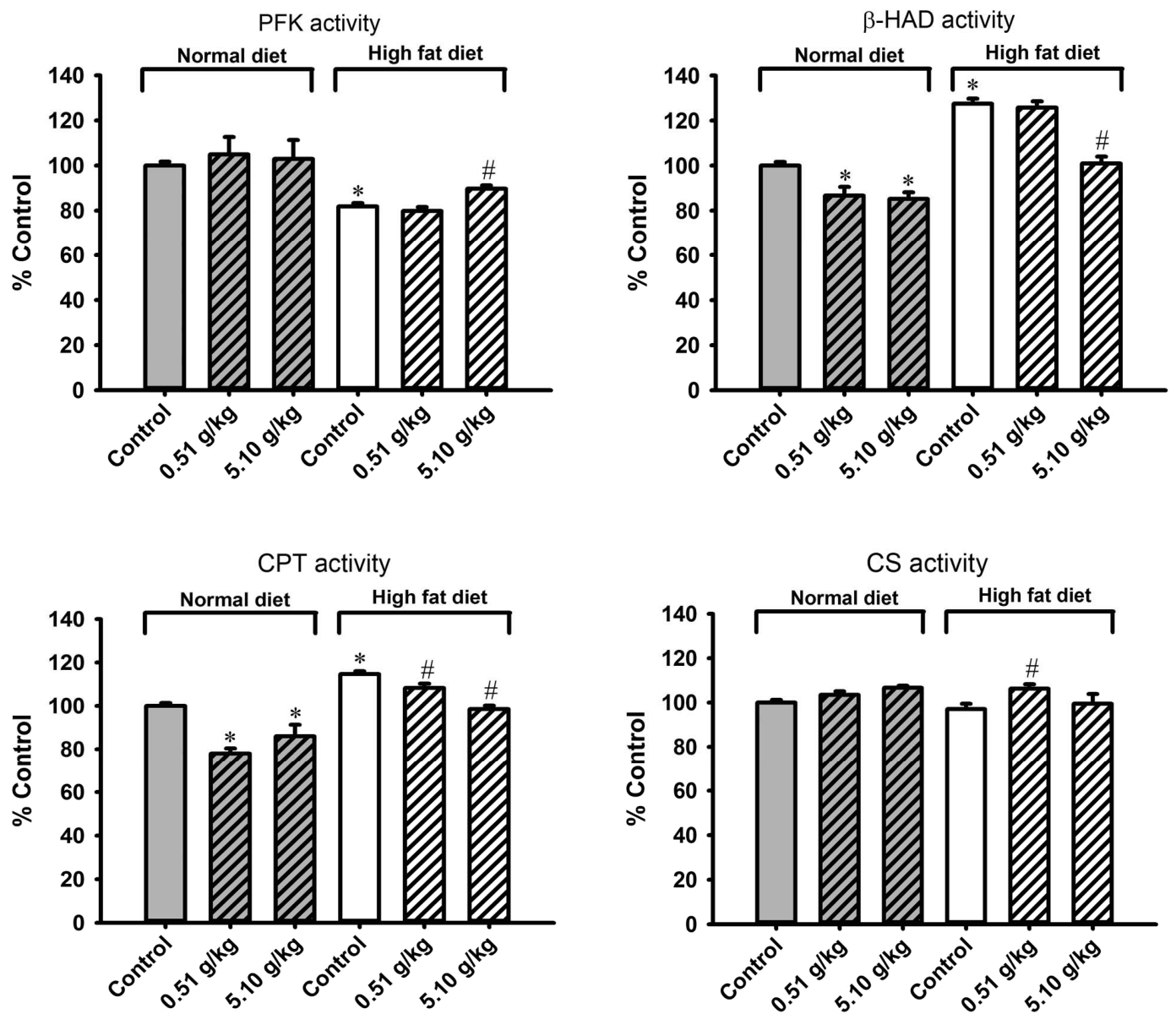

Figure 4. Effects of MCC treatment on metabolic enzyme activities in gastrocnemius muscle in normal diet (ND) and high fat -diet (HFD)-fed mice. Mice were sacrificed at $24 \mathrm{~h}$ after the last dosing of MCC as described in Figure 2. Activities of phosphofructokinase (PFK, ND control $=12.7 \pm 0.5 \mathrm{mU} / \mathrm{mg}$ protein), $\beta$-hydroxyacyl-CoA dehydrogenase $(\beta$-HAD, ND control $=$ $18.2 \pm 0.4 \mathrm{mU} / \mathrm{mg}$ protein), carnitine palmitoyl CoA transferase (CPT, ND control $=3.1 \pm 0.2 \mathrm{mU} / \mathrm{mg}$ protein) and citrate synthase (CS, ND control $=60.1 \pm 1.3 \mathrm{mU} / \mathrm{mg}$ protein) of muscle tissues were measured as described in materials and methods. Data were expressed as \% control, by normalizing with ND control. Values given are means \pm SEM, with $\mathbf{n}=10-15$. "Significantly different from ND control; " significantly different from HFD control.

of intensive research. It has been shown that visceral adipose tissue, which secretes adipokines, adiponectins and cytokines, can lead to insulin resistance and early stages of inflammation, thrombosis and hypertension [5]. Consistent with this, HFD feeding was found to cause glucose intolerance and insulin resistance in mice [33]. The hyperlipolytic state of the insulin-resistant visceral adipose tissue can cause an excessive accumulation of hepatic fatty acid, which in turn impairs the metabolic function of the liver, with a resultant hypertriglyceridemia [5]. Insulin resistance, in combination with adipocyte hypertrophy, was shown to elevate plasma glucose, TG and LDL-C levels [34].

The herbal formula MCC was found to suppress the body weight increase and decrease fat pad indices in HFD-induced obese mice. Given the predominant role of skeletal muscle tissue in mobilizing the lipid reservoir in the body [8], contemporary anti-obesity approaches aim at inducing mitochondrial uncoupling [35] and enhancing fatty acid metabolic status in skeletal muscle [36]. However, the MCC formula did not alter mitochondrial coupling efficiency or increase the activities of energy metabolic enzymes, such as PFK, $\beta$-HAD, CPT and CS in normal and HFD-induced obese mice. It is therefore unlikely that the MCC-induced weight reduction was mediated by inducing mitochondrial uncoupling or enhancing fatty acid oxidation in skeletal muscle. However, MCC can reverse the HFD-induced changes in $\beta$-HAD and CPT activities in skeletal muscle. This reversal change may be due to the reduction of fat absorption in gastrointestinal tract, with a consequent attenuation of HFDinduced $\beta$-HAD and CPT activation. This postulation is strengthened by a recent study which revealed the ability of the aqueous fruit extract of MC to inhibit glucose and 
tyrosine transport across rat everted intestinal sacs in situ [37]. Presumably, the decrease in body weight by MCC may be mediated by the suppression of lipid absorption in gastrointestinal tract, thereby attenuating the HFDinduced increases in body weight, fat pad indices, plasma lipid contents and lipid metabolic enzyme activities.

Overweight/obesity is found to be associated with metabolic syndrome (reviewed in [4]), which is characterized by atherogenic dyslipidemia, hypertension, hyperglycemia and insulin resistance, with a resultant increased risk of atherosclerotic cardiovascular disease [38]. In this connection, the weight reduction effect of MCC may be capable of producing beneficial outcome in dietinduced overweight/obese individuals. Further studies will investigate the role of individual component in the MCC formula in weight control.

\section{REFERENCES}

[1] D. W. Haslam and W. P. James, "Obesity," The Lancet, Vol. 366, No. 9492, 2005, pp. 1197-1209. doi:10.1016/S0140-6736(05)67483-1

[2] G. K. Singh, M. D. Kogan and P. C. van Dyck, "Changes in State-Specific Childhood Obesity and Overweight Prevalence in the United States from 2003 to 2007," Archives of Pediatrics \& Adolescent Medicine, Vol. 164, No. 7, 2010, pp. 598-607. doi:10.1001/archpediatrics.2010.84

[3] N. S. The, C. Suchindran, K. E. North, B. M. Popkin and P. Gordon-Larsen, "Association of Adolescent Obesity with Risk of Severe Obesity in Adulthood," The Journal of the American Medical Association, Vol. 304, No. 18, 2010, pp. 2042-2047. doi:10.1001/jama.2010.1635

[4] J. A. Knight, "Diseases and Disorders Associated with Excess Body Weight," Annals of Clinical \& Laboratory Science, Vol. 41, No. 2, 2011, pp. 107-121.

[5] J. P. Després, "Is Visceral Obesity the Cause of the Metabolic Syndrome?" Annals of Medicine, Vol. 38, No. 1, 2006, pp. 52-63. doi:10.1080/07853890500383895

[6] S. M. Grundy, "Metabolic Syndrome Pandemic," Arteriosclerosis, Thrombosis, and Vascular Biology, Vol. 28, No. 4, 2008, pp. 629-636. doi:10.1161/ATVBAHA.107.151092

[7] G. I. Shulman, "Cellular Mechanisms of Insulin Resistance," The Journal of Clinical Investigation, Vol. 106, No. 2, 2000, pp. 171-176. doi:10.1172/JCI10583

[8] A. Bonen, G. L. Dohm and L. J. van Loon, "Lipid Metabolism, Exercise and Insulin Action," Essays in Biochemistry, Vol. 42, 2006, pp. 47-59. doi:10.1042/bse0420047

[9] N. Musi, N. Fujii, M. F. Hirshman, I. Ekberg, S. Fröberg, O. Ljungqvist, A. Thorell and L. J. Goodyear, "AMPActivated Protein Kinase (AMPK) is Activated in Muscle of Subjects with Type 2 Diabetes during Exercise," Diabetes, Vol. 50, No. 5, 2001, pp. 921-927.

doi:10.2337/diabetes.50.5.921

[10] R. R. Wing, E. Venditti, J. M. Jakicic, B. A. Polley and
W. Lang, "Lifestyle Intervention in Overweight Individuals with a Family History of Diabetes," Diabetes Care, Vol. 21, No. 3, 1998, pp. 350-359. doi:10.2337/diacare.21.3.350

[11] E. Caveney, B. J. Caveney, R. Somaratne, J. R. Turner and L. Gourgiotis, "Pharmaceutical Interventions for Obesity: A Public Health Perspective," Diabetes, Obesity and Metabolism, Vol. 13, No. 6, 2011, pp. 490-497. doi:10.1111/j.1463-1326.2010.01353.X

[12] H. L. Huang, Y. W. Hong, Y. H. Wong, Y. N. Chen, J. H. Chyuan, C. J. Huang and P. M. Chao, "Bitter Melon (Momordica charantia L.) Inhibits Adipocyte Hypertrophy and Down Regulates Lipogenic Gene Expression in Adipose Tissue of Diet-Induced Obese Rats," British Journal of Nutrition, Vol. 99, No. 2, 2008, pp. 230-239. doi:10.1111/j.1463-1326.2010.01353.x

[13] L. L. Chan, Q. Chen, A. G. Go, E. K. Lam and E. T. Li, "Reduced Adiposity in Bitter Melon (Momordica charantia)-Fed Rats Is Associated with Increased Lipid Oxidative Enzyme Activities and Uncoupling Protein Expression," Journal of Nutrition, Vol. 135, No. 11, 2005, pp. 2517-2523.

[14] L. A. Nichols, D. E. Jackson, J. A. Manthey, S. D. Shukla and L. J. Holland, "Citrus Flavonoids Repress the mRNA for Stearoyl-CoA Desaturase, a Key Enzyme in Lipid Synthesis and Obesity Control, in Rat Primary Hepatocytes," Lipids in Health and Disease, Vol. 23, No. 36, 2011, pp. 1-5.

[15] C. L. Hsu and G. C. Yen, "Induction of Cell Apoptosis in 3t3-L1 Pre-Adipocytes by Flavonoids Is Associated with Their Antioxidant Activity," Molecular Nutrition \& Food Research, Vol. 50, No. 11, 2006, pp. 1072-1079. doi:10.1002/mnfr.200600040

[16] B. T. Wall, F. B. Stephens, D. Constantin-Teodosiu, K. Marimuthu, I. A.Macdonald and P. L. Greenhaff, "Chronic Oral Ingestion of L-Carnitine and Carbohydrate Increases Muscle Carnitine Content and Alters Muscle Fuel Metabolism during Exercise In Humans," The Journal of Physiology, Vol. 589, No. 4, 2011, pp. 963-973. doi:10.1113/jphysiol.2010.201343

[17] S. Reagan-Shaw, M. Nihal and N. Ahmad, "Dose Translation from Animal to Human Studies Revisited," The FASEB Journal, Vol. 22, No. 3, 2008, pp. 659-661. doi:10.1096/fj.07-9574LSF

[18] S. F. Leibowitz, J. T. Dourmashkin, G. Q. Chang, J. O. Hill, E. C. Gayles, S. K. Fried and J. Wang, "Acute high-Fat Diet Paradigms Link Galanin to Triglycerides and their Transport and Metabolism in Muscle," Brain Research, Vol. 1008, No. 2, 2004, pp. 168-178. doi:10.1016/j.brainres.2004.02.030

[19] W. S. Coelho, K. C. Costa and M. Sola-Penna, "Serotonin Stimulates Mouse Skeletal Muscle 6-Phosphofructo-1Kinase through Tyrosine-Phosphorylation of the Enzyme Altering Its Intracellular Localization," Molecular Genetics and Metabolism, Vol. 92, No. 4, 2007, pp. 364-370. doi:10.1016/j.brainres.2004.02.030

[20] H. Y. Leung, P. Y. Chiu, M. K. Poon and K. M. Ko, “A Yang-Invigorating Chinese Herbal Formula Enhances Mitochondrial Functional Ability and Antioxidant Capac- 
ity in Various Tissues of Male and Female Rats," Rejuvenation Research, Vol. 8, No. 4, 2005, pp. 238-247. doi:10.1089/rej.2005.8.238

[21] R. Crescenzo, D. Mainieri, G. Solinas, J. P. Montani, J. Seydoux, G. Liverini, S. Iossa and A. G. Dulloo, "Skeletal Muscle Mitochondrial Oxidative Capacity and Uncoupling Protein 3 Are Differently Influenced by Semistarvation and Refeeding," FEBS Letters, Vol. 544, No. 1-3, 2003, pp. 138-142. doi:10.1016/S0014-5793(03)00491-5

[22] M. J. Pagliassotti, D. Pan, P. Prach, T. Koppenhafer, L. Storlien and J. O. Hill, "Tissue Oxidative Capacity, Fuel Stores and Skeletal Muscle Fatty Acid Composition in Obesity-Prone and Obesity-Resistant Rats," Obesity Research, Vol. 3, No. 5, 1995, pp. 459-464. doi:10.1002/j.1550-8528.1995.tb00175.x

[23] S. N. Yun, S. J. Moon, S. K. Ko, B. O. Im and S. H. Chung, "Wild Ginseng Prevents the Onset of High-Fat Diet Induced Hyperglycemia and Obesity in ICR Mice," Archives of Pharmacal Research, Vol. 27, No. 7, 2004, pp. 790-796. doi:10.1007/BF02980150

[24] M. Siddiqua, K. Hamid, M. H. Ar-Rashid, M. S. Akther and M. S. K. Choudhuri, "Changes in Lipid Profile of Rat Plasma after Chronic Administration of Laghobanondo Rosh (LNR) - An Ayurvedic Formulation," Biology and Medicine, Vol. 2, 2010, pp. 58-63.

[25] G. P. Holloway, A. B. Thrush, G. J. Heigenhauser, N. N. Tandon, D. J. Dyck, A. Bonen and L. L. Spriet, "Skeletal Muscle Mitochondrial FAT/CD36 Content and Palmitate Oxidation Are Not Decreased in Obese Women," American Journal of Physiology-Endocrinology and Metabolism, Vol. 292, No. 6, 2007, pp. E1782-E1789. doi:10.1152/ajpendo.00639.2006

[26] S. L. Carter, C. D. Rennie, S. J. Hamilton and M. A. Tarnopolsky, "Changes in Skeletal Muscle in Males and Females Following Endurance Training," Canadian Journal of Physiology and Pharmacology, Vol. 79, No. 5, 2001, pp. 386-392. doi:10.1139/y01-008

[27] G. P. Holloway, A. Bonen and L. L. Spriet, "Regulation of Skeletal Muscle Mitochondrial Fatty Acid Metabolism in Lean And Obese Individuals," The American Journal of Clinical Nutrition, Vol. 89, No. 1, 2009, pp. 455S462S. doi:10.3945/ajen.2008.26717B

[28] S. R. Colberg, J. A. Simoneau, F. L. Thaete and D. E. Kelley, "Skeletal Muscle Utilization of Free Fatty Acids in Women with Visceral Obesity," The Journal of Clinical Investigation, Vol. 95, No. 4, 1995, pp. 1846-1853. doi:10.1172/JCI117864

[29] J. Y. Kim, R. C. Hickner, R. L. Cortright, G. L. Dohm and J. A. Houmard, "Lipid Oxidation Is Reduced in Obese Human Skeletal Muscle," American Journal of Physiology-Endocrinology and Metabolism, Vol. 279, No. 5,
2000, pp. E1039-E1044.

[30] H. Karlic, S. Lohninger, T. Koeck and A. Lohninger, "Dietary L-Carnitine Stimulates Carnitine Acyltransferases in the Liver of Aged Rats," Journal of Histochemistry \& Cytochemistry, Vol. 50, No. 2, 2002, pp. 205-212. doi: $10.1177 / 002215540205000208$

[31] N. Jiang, G. Zhang, H. Bo, J. Qu, G. Ma, D. Cao, L. Wen, S. Liu, L. L. Ji and Y. Zhang, "Upregulation of Uncoupling Protein-3 in Skeletal Muscle during Exercise: A Potential Antioxidant Function," Free Radical Biology and Medicine, Vol. 46, No. 2, 2009, pp. 138-145. doi:10.1016/j.freeradbiomed.2008.09.026

[32] S. L. Wijers, P. Schrauwen, W. H. Saris and W. D. Marken Lichtenbelt, "Human Skeletal Muscle Mitochondrial Uncoupling Is Associated with Cold Induced Adaptive Thermogenesis," PLoS One, Vol. 3, No. 3, 2008, p. e1777.

[33] G. Riccardi, R. Giacco and A. A. Rivellese, "Dietary Fat, Insulin Sensitivity and the Metabolic Syndrome," Clinical Nutrition, Vol. 23. No. 4, pp. 447-456. doi:10.1016/i.clnu.2004.02.006

[34] A. P. van de Woestijne, H. Monajemi, E. Kalkhoven and F. L. Visseren, "Adipose Tissue Dysfunction and Hypertriglyceridemia: Mechanisms and Management," Obesity Reviews, Vol. 12, No. 10, 2011, pp. 829-840. doi:10.1111/j.1467-789X.2011.00900.x

[35] S. Costford, A. Gowing and M. E. Harper, "Mitochondrial Uncoupling as a Target in the Treatment of Obesity," Current Opinion in Clinical Nutrition \& Metabolic Care, Vol. 10, No. 6, 2007, pp. 671-678. doi:10.1097/MCO.0b013e3282f0dbe4

[36] T. Goto, A. Teraminami, J. Y. Lee, K. Ohyama, K. Funakoshi, Y. I. Kim, S. Hirai, T. Uemura, R. Yu, N. Takahashi and T. Kawada, "Tiliroside, a Glycosidic Flavonoid, Ameliorates Obesity-Induced Metabolic Disorders via Activation of Adiponectin Signaling Followed by Enhancement of Fatty Acid Oxidation in Liver And Skeletal Muscle in Obese-Diabetic Mice," The Journal of Nutritional Biochemistry, Vol. 23, No. 7, 2012, pp. 768-776. doi:10.1016/j.jnutbio.2011.04.001

[37] M. F. Mahomoodally, A. Gurib-Fakim and A. H. Subratty, "Effect of exogenous ATP on Momordica charantia Linn. (Cucurbitaceae) Induced Inhibition of D-Glucose, L-Tyrosine and Fluid Transport across Rat Everted Intestinal Sacs in Vitro," Journal of Ethnopharmacology, Vol. 110, No. 2, 2007, pp. 257-263. doi:10.1016/j.jep.2006.09.020

[38] S. M. Grundy, "Metabolic Syndrome Pandemic," Arteriosclerosis, Thrombosis, and Vascular Biology, Vol. 28, No. 4, 2008, pp. 629-636. doi:10.1161/ATVBAHA.107.151092 